\title{
EDITH STEIN AND THE PROBLEM OF EMPATHY: LOCATING ASCRIPTION AND A STRUCTURAL RELATION TO PICTURE CONSCIOUSNESS
} ???? ????

\section{$\S 1$ Introduction}

The question which centrally concerns this paper is as follows. How, exactly, can it be possible for an Husserlian transcendental phenomenologist to assert the epistemic possibility of a phenomenally rich and veridical grasp of someone else's presently lived experience while still respecting Husserl's important insight into intersubjectivity contained in the Fifth Meditation that it is precisely a disjunction in subjective processes that is constitutive of the Other being other? It is a question which goes to the very heart of the "problem" to which Edith Stein refers in the title of her doctoral thesis Zum Problem der Einfühlung. ${ }^{1}$ According to Stein's account, as we shall see, during authentic empathy (conceived as the apperception and comprehension of another's mental life) the Other's primordial experience as such is not itself a primordial phenomenal datum at all, but remains veiled, at times attended to as the content of an objectifying apprehension, but always at one remove from what is originally given to the empathising consciousness. In the place of a claim to phenomenal unity with the Other, the idea is pervasive in Stein's thesis that empathy should properly be regarded as a particular kind of "seeing", not merely for the epistemic connotations of this word, but to the extent that one intuits something which is alien, and not something which belongs to one's sphere of ownness. She remarks, for example, that by a person's "walk, posture, and his every movement, we also 'see' 'how he feels"' [OPE 68-9]; that "I can see a person's sadness by his gait and posture" [OPE 78]; and that in the Other's expressions "we have [...] the spirit 'becoming visible' in the living body" [OPE 92. Emphases mine.] The advantage of Stein's "seeing" metaphor is that it conveys entirely fittingly, and in a way that Husserl himself would undoubtedly endorse, the sense in which empathy turns out to be quasiperceptual. But its disadvantage, I want to suggest, is that it glosses the stratified complexity of Stein's own understanding of empathy's essential structure, and risks implying its collapse into something intuitionally presentational. One of my principal contentions in this paper will be that a serious reading of the Steinian account must take it to be at least deeply suggestive of the idea that the respective lived experiences of self and Other should be understood to be phenomenally connected by a relation of resemblance. Surprisingly (in my opinion), the concept of a semblance is not one to which Stein explicitly appeals in her explication of the empathic understanding of the Other's experience. But 
it is, I intend to argue, a concept which is not only strongly implied in her descriptive account of empathy, but one whose proper place within the phenomenology of empathy can be corroborated by identifying, via a discussion of Husserl's mature understanding of the imagination, an homological relation between the essential structure of authentic empathy as Stein understands it, and that of the kind of perceptual re-presentation found in pictureconsciousness, as Husserl understands it.

Empathy, as I have just indicated, is for Stein fundamentally intuitional. This commitment to empathy's intuitional character leads Stein to reject the idea that empathy is an inferential accomplishment, as well as the idea that empathy is either an ascription of a primordial experience to somebody else (a view she attributes to Adam Smith) or an assumption about the Other's experience (a view she attributes to Meinong) [OPE 14]. Stein by no means asserts that acts of inference, ascription, and assumption might not serve us well, especially in cases in which empathy (as she conceives it) seems difficult to attain. Yet one of Stein's primary concerns in her book's second chapter 'The Essence of Acts of Empathy' is to develop a sufficiently precise initial conception of the empathic act to enable further fruitful phenomenological investigation to take place. Many conscious acts, intellectual or otherwise, may prove to be useful in the encounter with the Other, but only the intuitional comprehension of a foreign consciousness counts as a fulfilment of authentic empathy for Stein. This initial conception provides the basis for Stein's opening delineation of her precise field of phenomenological investigation.

Empathy thus conceived has the epistemological advantage of structurally avoiding what we might call projective deception, a risk logically inherent in the act of ascribing to someone else a mental state with which one is already familiar. Clearly, if ascription were the name of the empathic game, then one might plausibly be inclined, precisely on epistemological grounds, to ascribe to the Other a mental state with which one is familiar, rather than one with which one is unfamiliar. But therein lies the danger of projective deception that Stein explicitly recognises and seeks to avert. As Stein puts it,

If we take the self as the standard, we lock ourselves into the prison of our individuality. Others become riddles for us, or still worse, we remodel them into our image [...].

[OPE 116]

Yet Stein also remarks, in the same context as the passage just quoted, that "[o]nly he who experiences himself as a person, as a meaningful whole, can understand other persons". ${ }^{2}$ Thus, in spite of her admonition against imprisonment within the self, she also rejects the idea that introspection has no contribution to make to the accomplishment of empathy.

We find emerging here the way in which Stein intimates the deeply paradoxical nature of the problematic of empathy. In fact, there seem to be two distinct paradoxes at work. Firstly, we have a paradox to do with how empathy 
is to be conceptualised. On the one hand, empathy is supposed to grant the subject access (in some sense yet to be elaborated) to the Other's experience. But on the other hand, the empathiser is precisely not the subject of the empathised experience. This distinctive feature of the primordially experiencing subject in question being essentially alien differentiates empathy from other acts of intuitional presentiation such as memory, expectation, and "phantasy" in the Husserlian sense. Yet secondly, there seems to be a paradox arising from a tension between the intentional structure of the performance of empathy and the conditions for its possibility. On the one hand, the intuited intentional object is the Other's experience, and the ascription of one's own primordial experiences to the Other is held to be impermissible on pain of projective deception. But on the other hand, Stein also holds, as we recently noted, that "[o]nly he who experiences himself as a person, as a meaningful whole, can understand other persons" [OPE 116]. This is to say that no small degree of self-awareness is a condition for the possibility of the accomplishment of empathy. Both of these paradoxes require proper explanation if we are to avoid (as phenomenologists must) the philosophically unpalatable outcome that empathy should be taken to be at some level impenetrable or ultimately mysterious. Stein criticises Theodore Lipps (1851-1914) for gesturing toward an "inexplicable adjustment of our spirit" [OPE 37], instead of providing a detailed account of the constitution of foreign experience within consciousness. Unlike science and other disciplines, philosophy, as Stein observes, has no "domain into which it can push unsolved questions", and instead "must give the final answer, gain final clarity" $[O P E$ 38]. Let us begin by examining in more detail Stein's phenomenological attempt to elucidate and ultimately resolve these paradoxes.

\section{$\S 2$. Non-primordial "perception" of the Other's primordial experience}

Given Stein's explicit warnings about projective fallacy [OPE 87, 116], how are we to explain her implicit position that the most effective empathisers turn out to be remarkably self-aware individuals? I want to suggest that an important part of the answer to this question lies in Stein's view that empathy, for the Husserlian phenomenologist, involves apprehending not only the Other's lived experience as such, but also the latter's essential phenomenological structure, and that a sharing between self and Other of essential phenomenological structures of experience makes empathy possible. The assumption that the structures of conscious acts (including, of course, the structure of empathy itself) are universal across all human subjects is an implicit part of the entire Husserlian phenomenological project, a project within which Stein consciously situates herself. Indeed, even when Stein considers pathological conscious experience, she interprets it in terms of the absence of externally intelligible motivations, not in terms of deviation from the essential structures of conscious acts themselves [OPE 97]. 
This presumption of the universality of the structures of human experience provides us with an important explanation and justification for Stein's ostensibly introspective interest in the structure of emotion. What seems at first to be a purely subjective enquiry into the phenomenology of affectivity turns out to be an essential contribution to her governing interest in the experience of the Other. While Stein always insists upon the intuitional character of the experience of foreign experience, she is also, I would suggest, implying that empathy is partly attributive after all, not at the noetic level of lived experience, but at the reflective level of the essential structures of experience in general, and of emotion in particular. A constraint upon one's knowledge of the Other is held to be the extent of one's introspectively corroborating knowledge of the essential structures of one's own experience.

In fact, for reasons that will become clearer as this paper proceeds, it is Stein's understanding specifically of the emotions that turns out to be pivotal to what is most distinctive about her entire account of empathy. Let us therefore consider more closely Stein's account of the emotions, their place in conscious life, and their relation to other mental phenomena and activities. It is worth noting at the outset that it seems doubtful whether emotions should properly be regarded as conscious acts. Intentional acts like perceiving, imagining, remembering, and so on, are susceptible to volitional initiation by subjectivity. But it is not in the nature of the emotions to be subject to volitional initiation. While acts such as perception may properly be said to be performed, we do not in the normal course of events perform emotions. Emotions come upon us, and seem to well up, we might say, from the depths of our being. Emotions act upon and affect subjectivity. In this sense, then, the emotional "direction of action" is precisely the reverse of that occurring in what we standardly regard as conscious intentional acts.

Emotions in the first instance, then, are not really acts at all, but involve a subjective passivity in their simply being a part of our lived experience, of the world or of ourselves. In fact, actively attending to an emotion has a tendency to interrupt or dissipate its action. For this reason, if an emotion should have an intentional object, it is rarely about itself. If I am full of joy, then under normal circumstances it is not the joy that I am attending to, but something else, something over which I am joyful. Equally, it is possible that I may be full of joy without knowing why. Emotions which do not seem to have a readily identifiable intentional object may be classed as moods. Moods are not, on the face it at least, about something, but instead colour one's entire experience, not only of the world but of one's own conscious life [OPE 100].

Stein explicates the introspective experience of an emotion's apparent depth in terms of a correlation with one's value hierarchy [OPE 101]. Yet the capacity of an emotion to affect subjectivity is not solely determined by such a value correlation. Stein illustrates this point well with the observation that "the least 
mishap in our environment tends to excite us much more strongly than a catastrophe in another part of the world without our mistaking which event is more significant" [OPE 105]. This simple yet important insight leads to a conceptual differentiation between an emotion's depth and its "intensity", this latter term connected to a build-up of "energy" within one's subjective processes. In fact, Stein's use of the term "energy" in this context is something more than a metaphorical flourish. For one thing, natural limitations upon energy levels at the psycho-physical level are held to have implications for the individual's conscious life. In addition to this, a further important property of energy, as science understands it, turns out to propagate into subjective experience. As every physics student knows, when a spring is compressed or twisted it acquires potential energy, energy which not only is stored within the spring, but which the spring has a natural tendency to release when permitted to return to its normal shape. The emotions, according to Stein, exhibit an analogous property:

[A]s I live through the feeling, I feel it terminate in an expression[,] or release expression out of itself. Feeling in its pure essence is not something complete in itself. As it were, it is loaded with an energy which must be unloaded. [...] By nature [feeling] must always motivate something, must always be "expressed."

[OPE 51-2]

The above excerpt provides us with one of Stein's clearest intimations of the idea of a kind of phenomenal contiguity between feeling and expression. It is even a little surprising that Stein herself does not use the word "contiguity" at any point in her book. Yet there can be little doubt, I would suggest, that contiguity, carefully divested of its Humean connotations, is precisely the concept she has in mind here. Feelings are not essentially static entities, but instead are pregnant with a kind of movement, an essential movement toward expression. The movement toward expression is part of what feelings are. The frequent occurrences of the word "must" in the sentences just quoted shows us that Stein explicates this contiguity in terms of an exigency. But the exigency Stein has in mind here is not that of psycho-physical causality, but an exigency which is itself felt by the subject. It is the exigency of motivation, part of the lawfulness of conscious life. In one sense, the fact of this exigency means that the subject is prevailed upon, affected by, the immanent movement of feelings toward expression. But this lawfulness is not given to consciousness in the first instance as an alien force permitting of apprehension. The subject lives within the motivation and is inside its movement. Indeed, it is precisely the experience of living within the motivation that makes it meaningful. So motivation in this context is given to consciousness as a meaningful proceeding from feeling to expression.

When Stein uses the term "meaningful" in this context, she does not intend to imply that the lived experience of the motivation of feelings toward 
expression is necessarily either amenable to linguistic articulation or conceptually intelligible to the subject. This is consonant with the fact that complex emotion often becomes the object of artistic attention precisely by virtue of its seeming both deeply meaningful and yet, if not ineffable, at least resistant in its primordial experience to adequate articulation. And we also need to sharply distinguish the meaningfulness in question from familiarity. Feelings and their tendencies, of course, may not be at all familiar to the person having them. Instead, the meaningfulness that Stein has in mind here is precisely to do with dwelling within an emotion and its motivations. The motivation is meaningful to the subject because it is, so to speak, a pathway which itself belongs wholly within the territory of subjectivity, the sphere of ownness.

Stein remarks that one of the important properties of the living body [Leib] is that it is "the field of expression of the experiences of its ' $\mathrm{I}$ ". ${ }^{3}$ In the case of empathy founded upon bodily expression, the appresentation of foreign experience is an instance of the more general phenomenon of what Stein calls "co-givenness", in which what is co-given appears, strangely enough, "in that very peculiar way where what is not perceived can be there itself together with what is perceived" [OPE 57]. The Other's faculty of sensation, for example, is co-given with their bodily presentation, as is the transcendental 'I'. Yet what distinguishes the experience of bodily expression from these other cases of cogivenness is the apprehension of an intuitional unity connecting what is appresented with what is primordially given. As Stein observes, "[f]ear is at one with the cry of fear just as sadness is [at one] with the countenance" [OPE 78]. At the root of this phenomenal unity is the apprehension of a proceeding of what is primordially given from what is co-given. It seems to be a natural implication of Stein's position that this unity of proceeding must be understood as the empathic correlate of the subjective contiguity of expression that we discussed earlier. Yet it would seem the grasping of this unity is held to be intuitional rather than attributive, at least partly because the outward bodily expression on which the act of empathy in question is founded is (authentically) perceived. All the same, it is hard to see the ground for the constitution of such a unity if there were not some prior or background attribution of the structure of contiguity of expression that one experiences in oneself. The attributive dimension to empathy at the structural level is something that Stein leaves largely implicit, yet it can hardly be ignored if Stein's account of empathy's intuitional character is to be properly grounded and explicated.

Let us note that the co-givenness of the Other's feeling with their bodily expression that occurs during an act of empathy is not signitive in nature. Signitive givenness is characterised by a phenomenal disjunction between the given sign [Zeichen] and what it signifies, such as when, to cite Stein's own example, a flag announces that the king is in the castle. The relatedness between sign and signified is essentially arbitrary and governed by convention. At the 
same time, Stein also differentiates the contiguity experienced during empathy from the kind of connectedness found in what she classifies as an "indication" [Anzeichen], which she believes is exemplified in the relation of smoke to fire. Clearly, from what has just been said about signs, the relation between smoke and fire cannot strictly speaking be said to be signitive, because the smoke and fire are physically and causally connected entities, and their relatedness is therefore not arbitrary or a matter of convention. But equally there is a difference between the synthesis of smoke with fire, and the connectedness of a person's sad countenance with their feeling of sadness. The difference is that the phenomenal transition from smoke to fire, or similarly, I would suggest, from medical symptom to diagnosis, takes place at the thematic level. In this sense, indications are grasped in active rather than passive synthesis.

If the nature of the empathic phenomenal relation between an expression's appearance and that which is expressed is neither signitive nor indicative, according to Stein's understanding of these terms, then how is it to be denoted? From what has already been said, there is, in my opinion, a case for describing it as "contiguous" or "conjunctive", but Stein elects to call it a "symbolic" connection [Symbolzusammenhang], primarily, it would seem, to remain terminologically continuous with the work of Lipps, who made a similar distinction between signs and symbols. The disadvantage of Stein's choice of terminology here is that it obscures the phenomenological conception of contiguity that she works so hard to elucidate, both in her introspective account of the experience of one's own emotions, and in her empathic account of the experience of the Other's.

Stein, as I have just indicated, was not the first to become intrigued by the discovery of certain instances of co-givenness involving the structure of the constitution of a phenomenal unity which cannot be rendered intelligible by appealing to notions of signification or indication. Stein endorses and tries to illuminate the view she attributes to Johannes Volkelt (1848-1930) who believed, as Stein puts it, that " $[\mathrm{t}] \mathrm{he}$ experiences we comprehend in expressive appearances are fused [verschmolzen] with the phenomena of expression" [OPE 127, Note 102. Emphasis mine.] Accordingly, Stein on occasion adopts the term fusion [Verschmelzung] to characterise the phenomenal contiguity between feeling and its bodily expression [e.g. OPE 49, 58].

Yet, as Stein herself suggests, the most decisive influence upon her conception of what, it seems to me, we might reasonably call empathic conjunctive co-givenness comes from her doctoral supervisor Edmund Husserl, and in particular from his account of 'Expression and Meaning' provided in Logical Investigations. ${ }^{4}$ Husserl himself briefly remarks upon the intuitional character of empathy in the context of a discussion of expressions as they function in communication. While hearing another person speaking, Husserl observes, it is quite possible, for example, to "'see' their anger, their pain etc." 
[LI 190]. The kind of "seeing" that Husserl has in mind here provides the hearer with an outer but not an inner grasp of the speaker's experiences. The inner grasp, of course, is one of the things that Stein herself seeks to account for. And Husserl also speaks of "the experienced unity of sign and thing signified" involved in expression [LI 193]. As Stein makes clear, it is this Husserlian notion of an "experienced unity" which forms an important basis for her account of the symbolic connection in empathy founded upon bodily expression, and which also, Stein surmises, may well have prompted Lipps to differentiate between sign and symbol in his account of empathy.

\section{§ 3. Lived comprehension of the Other's lived experience}

The account of conjunctive co-givenness that we have discussed thus far has helped to illuminate the phenomenal nature of the particular phase of the empathic encounter that Stein refers to as emergence [OPE 10]. It is during emergence that one acquires an outer grasp of the Other's experience, apprehended as an intentional object. One "sees" the Other's feelings in a mode of intuition that Stein calls "the non-primordial parallel to perception" [OPE 10]. Yet empathy for Stein is not only a form of non-primordial intuition but also a form of understanding, and the empathic understanding that Stein has in mind goes beyond an empty objectifying awareness of the Other's experience, and beyond, too, an awareness simply of the kind of experience that the Other is having. Rather, Stein argues that it is part of the essential structure of acts of authentic empathy that they involve acquiring some apprehension of the nature of the Other's lived experience precisely as a lived experience. This is to say that a full realisation of authentic empathy, as Stein understands it, entails some knowledge of what it is to be the Other having the experience in question.

The acquisition of this inner grasp of foreign experience lies beyond the phase of emergence, and takes place in a subsequent phase that Stein calls the "fulfilling explication" [OPE 10]. During the fulfilling explication, there is a shift from objectifying intuition into pre-reflective lived experience, a lived experience in which, to put it loosely, we might say that one "dwells within the Other's experience". But what sense can it make to say that one dwells within the Other's experience? Husserl explicitly rules out, on the basis of his investigation into the encounter with the Other, an identity or confluence of primordial experience between self and Other, on the grounds that a disjunction of subjective processes turns out to be constitutive of the Other being other. ${ }^{5}$ Naturally, Stein is fully aware of this Husserlian finding, and it is clear that she does not dispute it. Her fundamental agreement with Husserl on this matter is demonstrated, for example, in her remark that "[the Other's] joy is neither given to us as primordial joy over the event nor as primordial joy over his joy. Rather it is given as this non-primordial act of empathy [...]" [OPE 14]. Empathy, in 
its relation to the Other's primordial experience, is non-primordial throughout all of its phases, even including the lived experience of the fulfilling explication.

Important as they are, the phases of emergence and the fulfilling explication do not fully delimit the scope of the empathic process. A reversion from the fulfilling explication to an objectification of the Other's experience, an objectification which now benefits from both an inner and an outer grasp of it, is something that Stein regards as a maturation of empathy, indeed a kind of epistemic telos toward which the experience of foreign experience has a tendency to move. In this third and final phase of empathy, one attains not only an external apperception of the Other's experience, but retains a noetic comprehension of what it is (for the Other) to be having such a primordial experience.

The reader familiar with Husserliana Volume XXIII (Phantasy, Image Consciousness, and Memory (1898-1925)) ${ }^{6}$ will recall in this context that Husserl has the important insight that acts of reproductive re-presentation (e.g. remembering, expecting, imagining) can involve a double focus in which the subject may attend to a re-presented impression either as the content of an objectified act or by dwelling within it as a lived experience. ${ }^{7}$ It is difficult to think of a reason for supposing that something similar is not capable of taking place during empathy. Provided that I have already acquired for the first time the fulfilling explication, it would seem that there is nothing to stop me from choosing either to continue to dwell within it or alternatively to switch out of it and instead objectify the Other's experience. And from the objectifying apprehension I may revert to the fulfilling explication and alternate between the two foci for as long as the Other's primordial experience continues to take place. Given this descriptive evidence, it is perhaps slightly surprising that Stein herself does not engage substantively with this idea of a double focus within the context of her investigation. As my exposition of her account has indicated, Stein configures the aspects of the empathic experience into a sequence of levels (their sequential character being intimated by her labelling them numerically and by her implying that in the optimal case one "go[es] through" them all [OPE 10]) rather than an accumulation of persistent perspectives which remain in the end co-present or at least co-available to the subject. The sequential characterisation is justified to the extent that the fulfilling explication, as Stein conceives it, cannot be performed unless the subject already believes, at some level, there to $b e$ a foreign primordial experience presently being had, and to the extent that this foreign primordial experience cannot be simultaneously objectified and adequately comprehended without the existential epistemic light of the fulfilling explication. What Stein fails to make explicit, however, is whether, or the degree to which, the different levels interpenetrate one another. Does one completely exit the fulfilling explication when one finally objectifies the Other's experience, or do the two levels continue in parallel? The problem 
with supposing the final objectification to be a discrete phase, self-sufficient in itself and independent of the fulfilling explication, is that it makes it difficult to justify the claim that the empathising subject is presently in a state of intuitional comprehension of the Other's primordial and presently occurring experience. It would be questionable to claim that one simply retains in memory the fulfilling explication, as this would appear to compromise empathy's quasiperceptual character, according to which something presently occurring is presently being "seen". If Stein's position is to be broadly sustained, then, we are now obliged to uphold the principle of the double focus, which Stein does not explicitly articulate or analyse. In this case, a Steinian position would have to argue that one's claim to comprehend the Other's lived experience is justified either by virtue of being able to switch back into the fulfilling explication whenever one wished, or by claiming that the fulfilling explication and the objectification are contemporaneous and interpenetrate one another within the empathiser's stream of subjective processes.

\section{$\S 4$. The phenomenal relation between the fulfilling explication and the Other's lived experience}

We must assume that Stein's choice of the phrase "fulfilling explication" is intended to suggest the idea that the Other's primordial experience is somehow (indeed, in a sense that we shall shortly seek to specify) fulfilled and given to consciousness during the act of empathy. Yet we noted earlier that the fulfilling explication phase cannot be understood to be the Other's primordial experience, on the grounds that I, as empathiser, am the one experiencing it. I am in fact having a lived experience which precisely is not the Other's primordial experience, yet which bears an important relation to the Other's primordial experience, a relation moreover, which carries epistemic weight. What exactly is this relation? One of the slightly surprising features of Stein's account is that she does not actually provide a very explicit answer to this question. Stein's account of the essential structure of empathy is expounded early in her thesis, and in my opinion could do with being revisited toward the end, to take into account the phenomenological findings of chapters III and IV (entitled 'The Constitution of the Psycho-Physical Individual' and 'Empathy as the Understanding of Spiritual Persons' respectively). Some kind of conclusion at the end of the book regarding the essential structure of acts of empathy would seem to be appropriate, not only in terms of reflecting the methodological priority of descriptive phenomenological work over eidetic findings, but also because the position Stein sets out in chapter II, 'The Essence of Acts of Empathy', requires further elaboration if the implications of Stein's overall understanding of empathy are to be fully understood.

I wish to pursue the idea that there is in fact a fully coherent understanding of empathy implicit within Stein's account, but that Stein herself does not 
appear to fully appreciate, or at least fully articulate, certain important structural implications which remain latent within her position. As I have already indicated, I believe the part of her thesis that could particularly benefit from clarification is her understanding of the fulfilling explication, the lived dimension of the empathic experience in which one "dwells within" a foreign experience, to the extent that it is intelligible and phenomenologically possible to speak of doing so. I believe the key to clarifying Stein's account lies in explicating the nature of the access to the Other's lived experience in terms of the constitution of a semblance. The justification for such an hypothesis may not be immediately obvious. Indeed, readers familiar with Hua XXIII will be reminded in this context of the way in which Husserl initially proposes an imagistic account of the imagination, only to ultimately run up against compelling phenomenological grounds for rejecting such a theory. Husserl replaces the imagistic theory with the view that acts such as remembering or imagining should properly be understood as reproductions of (respectively) posited or non-posited acts of perception. Importantly, Husserl recognises that such reproductions are capable of being nested or "iterated" within more complex acts. But he seems to have overlooked the possibility that image constitution might well be taking place within the context of iterated reproductions. My claim here is not that iterated reproductions always entail the constitution of an image, but that in particular iterated combinations of reproductions, a structure homologous to picture-consciousness is in fact liable to arise. ${ }^{8}$ Bearing this hypothesis in mind, let us return now to the problem of empathy.

A possible source of difficulty in properly understanding Stein's account lies in the different senses in which she uses the word "primordial". On the one hand, Stein wishes to stress the Husserlian idea that one does not have primordial access to the Other's primordial experience, a fundamental phenomenological stance which informs her problematisation of the views of both Lipps and Scheler. This view informs Stein's drawing of a sharp distinction between the "inner perception" of one's own mental life and the empathic intuition of the Other's, and explains why she makes assertions such as

If I experience a feeling as that of another, I have it given twice: once primordially as my own and once non-primordially in empathy as originally foreign.

[OPE 34]

And this is why she underscores the distinction between sympathetic primordial feelings of one's own and the feelings of the Other with which one is in sympathy. Primordial feelings of one's own in a sympathetic context are to be separated from the act of empathy, on pain of projective deception.

Yet on the other hand, it is also clear that Stein believes it to be constitutive of empathy that one should have primordial access to something, a primordial experience which illuminates the lived character of the Other's experience. So 
empathy is not regarded by Stein as "primordial" simply for the relatively trivial reason that it is, as she puts it, "primordial as present experience though nonprimordial in content" [OPE 10], but because empathy in its fullest manifestation is not merely an empty objectifying intuition but incorporates an essentially lived component, the component of the fulfilling explication.

And while I am living in the other's joy, I do not feel primordial joy. It does not issue live from my "I." Neither does it have the character of once having lived like remembered joy. But still much less is it merely fantasised without actual life. This other subject is primordial although I do not experience it as primordial. In my non-primordial experience I feel, as it were, led by a primordial one not experienced by me but still there, manifesting itself in my non-primordial experience.

[OPE 11]

Stein is suggesting here that the lived experience of dwelling within the Other's feelings somehow intimates beyond itself a different lived experience, namely that of the Other. In this sense, the fulfilling explication is intentional: it is a lived experience which is about another lived experience. The reason behind Stein's observation that the Other's joy is not given to the empathiser as "merely fantasised without actual life" must lie in the fact that it is (in the way that we considered earlier) constituted heteronomously on the basis of the Other's bodily expression. The Other's primordial experience is given as pregiven, as being prior to the empathic act, and furthermore governing the content of the fulfilling explication: "[...] I feel, as it were, led by a primordial [experience] not experienced by me but still there". With these words Stein clearly draws attention to the peculiar form of heteronomy constitutive of the act-character of the fulfilling explication. It is to be distinguished from the heteronomy found in acts of memory or expectation on the grounds of its being more radical by an order of structural magnitude, for not only is the empathised primordial experience subjectively transcendent to the empathic act but it is also apprehended as belonging to a foreign subjectivity, and I am aware of it "manifesting itself in my non-primordial experience". From this standpoint we may now observe that in registering descriptively the givenness of the foreign experience as such as an element of the fulfilling explication, it seems that Stein is in fact implicitly endorsing a notion of parallel focus: one is both having a lived experience of one's own and constituting the Other's as an intentional object.

Had Stein continued in the train of thought set out in the passage recently quoted, even for just a few more lines, it seems to me almost inconceivable that she should not have, at the very least, speculatively raised the idea that the phenomenal relation between the fulfilling explication and the Other's primordial experience is one of resemblance. The precise extent to which Stein herself contemplated this possibility is going to have to remain a matter for conjecture. Yet a combination of features of Stein's account makes the case for investigating the question of the quasi-pictoriality of empathy quite compelling. 
Firstly, empathy is held to be an intuitional act, but one which is not mistaken, by the careful phenomenologist, for having primordial access to the Other's primordial experience. This in itself does not point conclusively to pictureconsciousness, but it certainly raises it as a possibility. And it is worth recalling in this context that it would seem that Husserl initially pursued the imagistic theory of phantasy at least partly because phantasy is intuitional in character while at the same time not being mistaken for perception. That Stein should not in a similar fashion pursue an imagistic explication of empathy, even if only with a possible view to discarding it, is therefore somewhat surprising. Secondly, the content of the fulfilling explication is implicitly construed by Stein as being heteronomous in the sense that it is held to "speak", as it were, of an object which is not primordially present to consciousness. This corresponds to the way in which an image-object "speaks" of a picture-subject which is not primordially present.

Let us attempt to complete Stein's project and investigate the question of the "pictoriality" of empathy, that is, to verify the hypothesis that the essential structure of the empathic act is, in substantive respects, homologous to the structure of picture-consciousness. This will involve, in particular, showing that equivalents of the three distinct pictorial objectivities relevant to the Husserlian understanding of picture-consciousness turn out to be present within empathy, and fulfilling similar roles. We shall seek to locate, firstly, a governing intentional object implied within the experience (a picture-subject), secondly, an object grasped as a semblance (a semblance qua semblance or image-object), and thirdly, a containing object of some kind (a picture-thing).

In the cases of the image-object and the picture-subject, this task does not appear so difficult, for they have already emerged in the course of the preceding discussions. There can be no doubt that the governing intentional object in question is the Other's primordial lived experience. And the image-object with respect to this "picture-subject" must, as I have already suggested, be taken to be the fulfilling explication. In this respect, Stein has already done much of the work for us in registering and explaining the importance of these objectivities. Her only omission was to forget or overlook the important idea that the fulfilling explication as a lived experience should be understood precisely as a semblance of the foreign primordial experience, but it will, I believe, shortly become clear that this is the only convincing way of reconciling its epistemic value with its essentially non-primordial character.

A difficulty remains, however, with the delineation of a container object. We are not at liberty to disregard the importance of locating a "picture-thing" within the structure of empathy, for it emerges from the Husserlian account of picture-consciousness that the ability to switch the direction of one's attention between image-object and picture-thing turns out to be constitutive of pictureconsciousness itself. The fact that this does not take place during an act of pure 
phantasy contributed to the refutation of Husserl's early hypothesis about the pictoriality of such acts.

Let us consider the possibility that to the picture-thing corresponds the phase of empathy that Stein calls "comprehensive objectification". At this level of empathy, the foreign primordial experience is not only objectified but understood. But what is the basis for this understanding? The basis for the understanding is the insight provided during the lived experience of the fulfilling explication. So if Stein's "comprehensive objectification" purports to comprehend the Other's experience, then it must somehow involve the content of the fulfilling explication. In this connection, I want to suggest that there is a sense in which the comprehensive objectification may be said to open onto the fulfilling explication, which in turn opens onto the Other's primordial experience as an objectified intentional object. This view does indeed appear to be supported by the view I mentioned earlier regarding the parallel focus. According to the parallel focus view, both the objectified foreign experience and the fulfilling explication are simultaneously available to consciousness and permit of being attended to with varying degrees of emphasis. An elaboration of Stein's account is therefore required if the view that empathy conforms to the structure of picture-consciousness is to be sustained. The level of the comprehensive objectification must be understood not merely as temporally conditioned by the fulfilling explication, but in fact as incorporating it as well, and permitting of a return to it through a shift in the emphasis of the focus of one's attention. In this case the conditions for an homologous relation to pictureconsciousness may be said to be satisfied. Our picture-thing is the comprehensive objectification; our image-object is the fulfilling explication; and our picture-subject is the foreign primordial experience.

The finding that is now emerging is that the co-givenness of the foreign lived affective experience is to be explicated as the heteronomous constitution of a felt image-object on the basis of the Other's perceptually given bodily expression. But in this imaginational heteronomy, I am not imagining having the Other's experience for myself: I am imagining being the other person having the experience in question. Even more precisely, I believe that in the final and fully explicated analysis, we must say that there are in fact two distinct acts going on in the fulfilling explication. I am imagining being the other person, and then within this act of imagining, I am imagining having the experience in question. It would seem that empathy is performatively stratified in this way because having the experience in question is in truth merely a factual, and not an essential, part of being the other person. The kinds of experience of particular interest to us in this paper, such as feeling joyful, sad, or angry, are being considered as contingent experiences: joy over an examination result; sadness over a bereavement; anger over a stolen item of jewellery. For this reason, imagining having the foreign experience is not an essential part of imagining 
being the Other. In this sense, it would seem there is an essential fissure in the performance of the fulfilling explication. We are dealing at root, I would suggest, with an iteration of acts of the imagination.

On at least two occasions, Stein implicitly registers the idea that the fulfilling explication must involve a cumulation of distinct acts of the imagination. In the context of discussing the difference between empathy and inner perception (a difference she attributes to the lived character of the fulfilling explication) Stein refers to the fulfilling explication as "[t]he level [of empathy] where I am at the foreign 'I' and explain its experience by living it after the other [...]" [OPE 34]. Then later on while referring specifically to empathy based upon bodily expression, Stein appears to summarise the fulfilling explication by stating that "I project myself into the foreign living body, carry out the experience already co-given to me as empty with its countenance, and experience the experience ending in this expression" [OPE 82]. In these passages, Stein sets out a temporal series of aspects of the performance of the fulfilling explication. But there can be little doubt that, beyond this sequencing, Stein must also be implicitly committed to a nesting of the acts she delineates. One cannot empathically carry out the foreign experience if one does not remain transposed into the foreign subjectivity. In fact, it is the imaginative transposal into the other person which is responsible for the very alterity of the fulfilling explication, and without which the fulfilling explication could not be said to be experienced as a semblance of what is radically other, the Other's primordial experience, as experienced by the Other. So the explication of nested acts within the fulfilling explication underpins the claim that the Other's experience is given in the manner of a semblance, a finding which in turn informs the discovery that empathy conforms to an essential structure homologous to that of pictureconsciousness.

\section{§ 5. Conclusion}

Let us take a few moments now to reflect upon where our investigation into Edith Stein's account of the problem of empathy has taken us. For Stein, part of the tremendous significance of empathy is that it is capable of disclosing not only the nature of someone else's present experience, but features of the essential structure of the human person, features which could not be properly intuited and verified on the basis of introspection alone. Yet if Stein appears to grant empathy some kind of epistemic upper hand over introspection, such a privileging is mild, and cannot by any means be taken to imply the dispensability of introspection. The two modes of intuition are held to have an essentially reciprocal relationship of mutual corroboration and correction. Selfawareness, no matter how attentive and profound, cannot by itself solve the riddle of the Other. But it can provide important evidence relating to the essential structures of experience at the personal level, such as the correlation 
of feelings with values, and the nature of the chain of motivations running from values to actions. What Stein seems to leave unsaid is that the fact that introspection is capable of disclosing and corroborating such findings implies that empathy, notwithstanding its intuitional character, properly has an ascriptive dimension at the level of the structures of experience, and, of particular interest to the concerns of this paper, the structure of emotion. But I think it must be precisely this ascriptive property that Stein has in mind when she remarks that "[o]nly he who experiences himself as a person, as a meaningful whole, can understand other persons" [OPE 116]. Understanding empathy's ascriptive dimension as applying at the level of the structures of experience explains the paradox that the most effective empathisers should turn out to be remarkably self-aware individuals who nonetheless avoid the epistemic dangers of projective deception, and succeed in intuiting and understanding an experience which is essentially not theirs.

The kind of understanding of the foreign experience that interests Stein is not in the first instance conceptual, but instead takes the form of a lived experience which I have characterised as a kind of "dwelling within" the Other's conscious life. One of the important philosophical problems that Stein seeks to address is the explication and rendering intelligible of the ostensibly paradoxical claim that in the performance of empathy one is having an experience which precisely is not one's own. As we noted, the principal constraint imposed by transcendental phenomenology upon obtaining an answer to this question lies in the Husserlian view that a disjunction of subjective processes turns out to be constitutive of the Other being other. Stein's proposed solution to this problem involves two extremely important phenomenological insights. Firstly, she implies that the lived experience of the fulfilling explication carries an essential character of non-primordial heteronomy in relation to the foreign primordial experience, and that the latter is only objectified, and not itself lived by the empathising subject. Secondly, she implies that a condition for the possibility of such a fulfilling explication is a distinct and phenomenologically prior act of transposal into the motivations of the foreign personality. Without this prior act of personal-level transposal, the performance of the range of empathic activities described by Stein is curtailed, and cannot proceed beyond the emergent level of an empty objectification of essential features of the Other's experience. What Stein fails to properly recognise and make explicit, however, is that this nested structure of heteronomous acts of the imagination has an important implication for the way in which the foreign experience is itself experienced, namely that the fulfilling explication is given in the manner of a semblance, and that empathy essentially conforms to an intentional structure homologous to that of picture-consciousness. In this paper, it has only been possible to substantiate this conclusion by trying to develop Husserl's mature understanding of the imagination in certain ways, notably through a notion of parallel focus, and 
through a careful analysis of the structural possibilities inherent in the amenability of reproductions to nesting. Even so, it is surprising that Stein seems to have held back from at least raising the possibility that the Other's primordial experience could be given to the empathising consciousness in the manner of a semblance, although it is reasonable to assume that a contributory factor behind this omission lies in Husserl's sharp differentiation between the structure of reproductive representation, of which Stein took empathy to be a sui generis example, and that of the kind of perceptual representation found in picture-consciousness.

??? university

\section{References}

1. Edith Stein's doctorate was undertaken under the supervision of Edmund Husserl and awarded in 1916 at the University of Freiburg in Breisgau. German text: Stein, E., Zum Problem der Einfühlung, Freiburg: Herder, 2008. Its English translation, (Stein, E., On the Problem of Empathy, Trans. W. Stein, Washington D.C.: ICS Publications, 1989), is hereafter abbreviated to $O P E$.

2. $O P E$ 116. Stein's understanding of the empathic act is influenced by specialised discourses and debates surrounding the theory of the humanities or cultural sciences [Geisteswissenschaften]. She finds it noteworthy, for example, that Ranke expressed a desire to somehow " "erase' his self in order to see things 'as they were'." But there can be little doubt that Stein herself rejects any notion of self-erasure or self-nihilation as essentially unphenomenological. Instead, although critical of Dilthey's psychologism, Stein indicates that she is sympathetic to his view that " $[\mathrm{t}]$ he interpretive faculty operating in the cultural sciences is the whole person".

3. OPE 57. More precisely, I take Stein's detailed view to be that the body is not the only field of expression for the emotions, but rather the primal one, for she observes that the imagination may also, on occasion, serve as a domain of expression [OPE 52].

4. Husserl, E., Logical Investigations (1900/1901) Vol. 1, Ed. D. Moran, Trans. J.N. Findlay, Abingdon and New York: Routledge, 2005. Hereafter abbreviated to LI.

5. Husserl, E., Cartesian Meditations: An Introduction to Phenomenology (1931), Ed. D. Moran, Trans. D. Cairns, Dordrecht: Kluwer Academic Publishers, 1999, §50, p.109.

6. Husserl, E., Phantasy, Image Consciousness, and Memory (1898-1925), Trans. J.B. Brough, Dordrecht: Springer, 2005. Hereafter also referred to as Hua XXIII.

7. Ibid., p.672. For reasons that will become clearer as we proceed, it will shortly become appropriate to refine this idea by considering the possibility that this double focus could in fact turn out to be a parallel focus permitting of variations in emphasis between its two aspects, between which the performing subject is in principle free to switch attention back and forth as he or she pleases.

8. To see the plausibility of this idea, consider the case of remembering imagining something. Suppose I imagine viewing St. Paul's Cathedral, and that later on, I remember my imagining viewing St. Paul's Cathedral. During the second act, I am not free to imagine St. Paul's Cathedral in any way that I wish. The manner in which St. Paul's Cathedral appears in the second act is constrained by the way in which it appeared when I imagined it earlier. 